\title{
Guest editorial: 20th international meshing roundtable special issue
}

\author{
William Roshan Quadros
}

Published online: 5 June 2014

(C) Springer-Verlag London 2014

The 20th International Meshing Roundtable (IMR) committee is pleased to publish the special journal edition of the 20th IMR conference held on October 23-26, 2011 in Paris, France. Sandia National Laboratories started the IMR conference series in 1992 as a small meeting of likeminded companies and organizations striving to establish a common focus for research and development in the field of mesh and grid generation. Sandia National Laboratories continues to organize the IMR, which has become recognized as an international focal point annually attended by researchers and developers from dozens of countries around the world.

The 20th IMR is the first time the conference was held outside the US territory, which resulted in a significant increase in participation from European countries. The 20th IMR included researchers and developers from academia, national labs and industry in a stimulating, open environment to share technical information related to mesh generation and general pre-processing techniques. The 20th IMR was one of the best attended with 54 papers submitted, among which 34 papers were accepted. The committee invited the top 10 papers with best reviews to submit their work for this special issue, and 9 papers eventually appeared in this special issue. The papers in this volume present theoretical and novel ideas and algorithms with practical potential in computational engineering, geometric modeling, and computer graphics. These papers highlight some of the latest advances in these areas in research and industrial settings.

We would like to thank the authors, the reviewers, and the publishing staff for their efforts to make this special journal issue possible.

On behalf of the 20th International Meshing Roundtable Committee.

W. R. Quadros ( $₫)$

Sandia National Labs, PO Box 5800, MS 0897 Albuquerque,

NM 87185- 897, USA

e-mail: wrquadr@sandia.gov 